\title{
Donating time to charity: working for nothing?
}

\author{
By Yu Aoki
}

IZA, HERU and Department of Economics, University of Aberdeen, Dunbar Street, Old Aberdeen, AB24

3QY, United Kingdom; e-mail: y.aoki@abdn.ac.uk

\begin{abstract}
This paper studies the causal effect of the voluntary contributions of labour to local services, in the form of voluntary provision of daily care to the elderly, on elderly mortality. To identify the causal effect, I exploit the earthquake that occurred in midwestern Japan in 1995 as a natural experiment inducing exogenous variation in the level of contributions. Based on a comparison of mortality between the municipalities that recorded no or little loss of life due to the earthquake but experienced a sharp increase in the level of contributions, and the nearby municipalities that were not hit by the earthquake, I find that the voluntary provision of daily care to the elderly significantly reduced elderly mortality. A series of robustness checks and falsification exercises are conducted to confirm that the results are not driven by the direct effects of the earthquake.
\end{abstract}

JEL Classification I10, J14, J22.

\section{Introduction}

Millions of people across the world work for free. Globally, $21 \%$ of individuals volunteered in 2013 on average, and in particular, the United States recorded the highest volunteer participation rate of $44 \%$ among developed countries. ${ }^{1}$ Furthermore, the hours of work contributed are not trivial: for instance, Americans volunteered approximately 7.7 billion hours in $2013,{ }^{2}$ corresponding to nearly 4 million full-time equivalents and 38 hours per working-age person. Despite the significant amount of voluntary contributions of labour, formal research on its potential benefit is scarce. Among the various types of voluntary contributions of labour, this study focuses on voluntary work providing daily assistance to the elderly. Evaluating the impact of such voluntary work is particularly important due to ongoing global population ageing, which has resulted in rapid growth in the need for support for the elderly. For governments to consider encouraging voluntary work as a means to help accommodate the growing needs of an ageing population, they need to be informed of its benefits. Among various possible benefits of this type of voluntary work, this study investigates its effect on elderly mortality.

A major challenge in identifying the causal effect of voluntary work on mortality is the endogeneity of volunteering. There may be more voluntary contributions of labour in municipalities

\footnotetext{
${ }^{1}$ The participation rates are defined for individuals aged 15 or above and are obtained from the World Giving Index 2014, which includes data from 135 countries (Charities Aid Foundation, 2014). The figures are based on volunteer participation during one month prior to surveys conducted in 2013.

${ }^{2}$ Hours contributed are obtained from the Corporation for National and Community Service (2014). The value presented is estimated hours spent on formal voluntary activity.
} 
with a large number of people at high risk of mortality, such as the elderly. Thus, it is difficult to conclude if the level of volunteering affects mortality or vice versa. Equally, unobserved heterogeneity across municipalities that affects both mortality and the level of volunteering (e.g., the quality of local healthcare services) may bias estimates of the effect of volunteering.

To identify the causal effect of voluntary work on mortality, I use the variation in volunteering caused by the Kobe earthquake, which occurred in the midwestern part of Japan in 1995. The level of volunteering considerably increased in municipalities hit by the earthquake relative to other municipalities that did not hit by the earthquake. Based on a comparison of mortality between the municipalities that recorded no or little loss of life due to the earthquake but experienced a sharp increase in the level of volunteering, and the nearby municipalities that were not hit by the earthquake, I find that volunteering significantly reduced mortality among persons in two age cohorts, namely, those in their 70s and in their 80 s or older.

To the best of my knowledge, this is the first paper to examine the causal effect of voluntary work on the recipients of voluntary service with an arguably credible identification strategy. Surprisingly, the effects of voluntary work, especially its effects on the recipients of voluntary service, have been overlooked despite its enormous potential effects given the scale of volunteer activity. Instead previous research on voluntary work conducted by economists primarily focuses on determinants of the supply of volunteer labour, seeking to understand why people work for free (e.g., Freeman, 1997; Duncan, 1999). A notable exception is the work conducted by Meier and Stutzer (2008) that investigates the causal effect of volunteering on life satisfaction of volunteers using a change in opportunities to volunteer caused by changes in firm infrastructure following the reunification of Germany. The studies most closely related to the topic of volunteering are those on contributions of money, as opposed to labour, to charity that investigate people's motivations to donate and optimal ways of fund-raising (e.g., DellaVigna et al., 2012; Carlsson et al., 2015), the topics that have been extensively analysed by economists.

The remainder of the paper proceeds as follows. Section 2 explains the earthquake and its effect on voluntary contributions of labour. Section 3 discusses the identification strategy, while Section 4 describes the data sources. Section 5 discusses the main empirical findings and investigates the type of death that is affected by voluntary work to infer the mechanisms through which volunteering affects mortality. Section 6 examines the robustness of the main findings, particularly aiming to ensure that the main results are not driven by the direct effects of the earthquake. Finally, Section 7 discusses policy implications and concludes the paper.

\section{The earthquake and voluntary work}

The Kobe earthquake occurred in January 1995 with its epicentre in Hyogo Prefecture (see Fig. 1). The earthquake recorded a magnitude of 7.3 and the maximum possible intensity of seven on the Japanese intensity scale in the southern part of Hyogo Prefecture. ${ }^{3}$ The earthquake caused the second largest loss of life in post-war Japan: 6,434 people were killed, 43,792 people were injured, and infrastructure such as water and electricity were seriously disrupted (Fire and Disaster

\footnotetext{
${ }^{3}$ The seismic intensity of seven is assigned to an earthquake strong enough to alter a landform or cause a landslide.
} 
Management Agency, 2006). During 1,500 years that earthquakes had been recorded in Japan, Kobe had never been hit by major earthquakes, lending credibility to the notion that the city was safe from seismic activity (United Nations Centre for Regional Development, 1995). Local governments, businesses, and private households did not anticipate a large earthquake in this area and were not prepared for this large shock. For example, only three percent of property in the Kobe area was covered by earthquake indemnity as opposed to $16 \%$ in Tokyo (Edgington, 2010). Thus, the earthquake arguably provides an ideal natural experiment that generates exogenous variation in volunteering.

\subsection{How did the Kobe earthquake affect volunteering?}

Shortly after the earthquake, a large number of volunteers from different parts of Japan gathered in the disaster area to provide emergency support, such as transporting relief and providing nursing. A total of 1,377,000 people volunteered over the year following the earthquake, approximately $70 \%$ of whom were volunteering for the first time (Fire Service and Disaster Prevention Division, 1996). The large-scale volunteer activities following the earthquake were broadcast as a new social phenomenon and subsequently served to popularize volunteer activity in Japan, as is demonstrated by the fact that the year 1995 is called 'volunteer gannen', meaning 'the starting year of volunteerism'. 4

Suga (2011) states that the sharp increase in volunteering helped change the perception of voluntary work from the activities that sacrifice oneself to render service to others to something that brings self-satisfaction by helping others. The earthquake may thus have helped popularize volunteer activity by making the public aware of a benefit it brings them. In fact, existing literature points out obtaining intrinsic rewards as an important motive for participating in voluntary work. For example, Becker (1974) suggest that individuals help others because they have altruistic preferences and enjoy an increase in the well-being of others, and Andreoni (1989) suggests that people volunteer because they receive a warm glow via the act of giving.

The earthquake may have also helped increase the level of voluntary contributions of labour by making people more altruistic. For example, Vollhardt and Staub (2011) argue the case of 'altruism born of suffering', meaning that the experience of suffering increases prosocial attitudes and behaviour. They find that individuals who experienced adverse life events, including natural disasters, are more likely to exhibit prosocial response, in the forms of everyday volunteering and providing short-term emergency help, when confronted with others in need. Experimental evidence also suggests that people who experienced adverse life events are more prosocial under a certain condition (e.g., Becchetti et al., 2014).

\footnotetext{
${ }^{4}$ Although there has been a long tradition of mutual support among, for example, family members and neighbours, organized voluntary work where individuals donate their time to help strangers was not popular activities among the public prior to the earthquake, unlike other countries that have a long tradition of organized voluntary work such as the United States.
} 


\subsection{What is voluntary work?}

In this paper, voluntary work is defined as activities conducted by and/or for residents in Hyogo Prefecture in a voluntary and autonomous manner that aim to contribute to the well-being of the public. ${ }^{5}$ Specifically, I focus on voluntary work conducted by the volunteers registered with or known to the Hyogo Council of Social Welfare. ${ }^{6}$ Those volunteers engage in activities that primarily target the elderly. The primary activities of the volunteers are delivery of meals, visits to homes, hospitals and care homes for a chat, organisation of community gatherings, and assistance with daily tasks (e.g., housework). Figure 2 summarizes the characteristics of volunteers. As shown in panel A, the vast majority of volunteers are female. Panel B indicates that individuals in their 60s account for the largest proportion of volunteers, 25.4\%. People in their 50s are the second largest, $23.2 \%$, implying that these two age bands account for approximately half of the volunteers. Presumably, females in these age bands have already completed child rearing and are devoting part of their time to volunteering. The occupational composition of volunteers presented in panel $\mathrm{C}$ indicates that housewives alone account for nearly half of volunteers.

\section{Identification strategy}

I now turn to a discussion of the identification strategy. This study explores the causal effect of volunteering on mortality by regressing mortality on a measure of volunteering, controlling for various socio-economic indicators. The following model is specified:

$$
\ln (\# \text { deaths })_{i t}=\beta_{0}+\beta_{1} \ln (\# \text { volunteers })_{i t}+X_{i t}^{\prime} \gamma+v_{i}+\tau_{t}+\varepsilon_{i t}
$$

where $\ln (\# \text { deaths })_{i t}$ represents the $\log$ of the number of deaths in municipality $i$ in year $t$, and $\ln$ (\#volunteers $)_{i t}$ is the number of volunteers in log. The time varying socio-economic characteristics, $X_{i t}$, and the parameter $\gamma$ are $K \times 1$ vectors, where $K$ is the number of socio-economic indicators. $v_{i}$ and $\tau_{t}$ are municipality and year fixed effects, respectively, and $\varepsilon_{i t}$ is the disturbance term.

The main coefficient of interest is $\beta_{1}$ which measures the effect of volunteering on mortality. An econometric issue in the estimation of eq. (1) is the endogeneity of volunteering. Specifically, unobserved heterogeneity such as the quality of local healthcare services may affect both mortality and the level of volunteering. It may also be the case that there are more volunteers in municipalities with a large number of vulnerable individuals such as the elderly (reverse causality). If it is the case, the ordinary least squares (OLS) estimator for $\beta_{1}$ is biased. More precisely, a possible negative effect of volunteering on mortality is positively biased, resulting in a bias towards zero.

\footnotetext{
${ }^{5}$ The following activities are not included in volunteer activity: the activities that (i) are for profit, (ii) aim to spread a certain religious belief, (iii) aim to promote or oppose a certain political doctrine, and (iv) aim to support or oppose a candidate for a public office, a public officer or a political party.

${ }^{6}$ There are individuals not registered with the Hyogo Council of Social Welfare but known to volunteer. They are members of community organizations such as women's associations, neighbourhood councils, students associations, local elderly clubs, etc. There may be other volunteers not registered with and not known to the council. Possible implications of unregistered and unknown volunteers will be discussed in Section 5.
} 
An unbiased estimator can be obtained by using the instrumental variable (IV) estimator, which requires an instrument giving exogenous variation in volunteering.

In this paper, earthquake damage is used as an instrument for volunteering. For the earthquake damage to be a valid instrument, I require the assumptions that the earthquake damage does not appear in eq. (1) and is not correlated with any other determinants of elderly mortality than volunteering. However, the nature of the instrument raises serious concerns about the validity of the assumption. Firstly, 6,434 people were killed by the earthquake, indicating that the identifying assumption does not hold in the year 1995. Secondly, apart from the deaths that occurred in the year 1995, the earthquake may have long-run effects on mortality. For instance, the earthquake may have disproportionately killed frail individuals such as the elderly, leading to a lower mortality afterwards because relatively fitter individuals survived. Thirdly, public resources provided subsequent to the earthquake may have also affected mortality. In order to address these types of concerns, two strategies are employed: namely, (i) omitting the year 1995 from the sample and (ii) retaining in the sample only municipalities that recorded no or little loss of life due to the earthquake.

Omitting the year 1995 would address the temporary change in mortality in the aftermath of the earthquake. The earthquake occurred in January 1995, and the peak number of 316,678 persons were displaced in January 1995. The number of displaced persons steadily decreased as the (re)construction of homes and temporary housing proceeded, and 97\% of displaced persons left emergency shelters by August 1995. The earthquake also caused serious damage to infrastructure such as water and electricity. However, repairs of the infrastructure were extremely rapid. Electricity and phone lines were repaired by the end of January 1995, and water and gas supplies resumed by the end of April 1995. The earthquake also severely damaged medical facilities. As of January 1995, 33\% of hospitals and clinics in Hyogo Prefecture were closed due to damage to buildings or disruptions in infrastructure. Within a month, however, $70 \%$ of hospitals and clinics had resumed operations, and subsequently $93 \%$ had resumed operations by the end of 1995 . Thus, omitting year 1995 from the sample also addresses the possibility of an increase in mortality induced by temporary disruptions to daily life, infrastructure, and medical facilities.

Nevertheless, there may still be a concern that the damage caused by the earthquake had longterm consequences on mortality even after omitting year 1995. For example, the earthquake may have selectively killed weak individuals, implying that those who survived the earthquake might be the fittest individuals with a low risk of mortality. It could also be the case that the mental stress caused by the earthquake, deterioration of chronic illnesses due to disruptions to daily life (e.g., living in emergency shelters) and public resources provided in disaster areas had a persistent effect on mortality even after 1995. To address this type of concerns, I further restrict the sample and retain only the municipalities that recorded no or little loss of life due to the earthquake, although the results using the full sample will also be presented to investigate whether there is evidence of selective mortality and how sample specifications affect estimation results. Figure 3 shows municipalities in Hyogo Prefecture according to their damage intensity. Among the set of municipalities with damage, the grey area corresponds to a subset of municipalities that recorded 
little to moderate damage, while the black area corresponds to those severely damaged. ${ }^{7}$ These are the four municipalities closest to the epicentre, the location of which overlaps with the area that recorded the highest seismic intensity of seven on the Japanese intensity scale. These municipalities lie along the faults that caused the earthquake (see Appendix 1) and account for a substantial amount of the physical damage due to the earthquake: $98 \%, 85 \%$, and $88 \%$ of the total deaths, serious injuries and complete destruction of homes, respectively.

Omitting these municipalities has several important implications. Firstly, municipalities retained in the sample recorded no or little loss of life due to the earthquake, implying that even if the earthquake selectively killed vulnerable individuals, it would have happened outside the sampled municipalities. Secondly, as mentioned previously, medical facilities were heavily damaged, a large number of individuals were displaced, and public resources were provided in the disaster areas subsequent to the earthquake, which may have had long-term consequences on mortality. Omitting municipalities severely damaged by the earthquake addresses these types of concerns, as emergency shelters, medical facilities that experienced severe damage, and the areas targeted for providing extensive public support were located outside the sampled municipalities. ${ }^{89}$

Table 1 reports the average destruction due to the earthquake in the treatment and control municipalities. A municipality is categorized as treated if the municipality recorded a positive level of earthquake damage measured by the number of individuals slightly injured, although different measures of earthquake damage will be used in the section of robustness checks. After omitting the four most severely damaged municipalities, my sample consists of 27 municipalities in the treatment group and 57 municipalities in the control group. As expected, the share of individuals who died in the treatment group, $0.01 \%$, is not substantial because severely damaged municipalities are excluded, implying that the issue of selective mortality is unlikely to be a severe concern in the sampled municipalities. The share of individuals with serious injuries, $0.06 \%$, is again not substantial, while approximately $0.50 \%$ of people experienced minor injuries in the treatment municipalities. Destruction of homes was more substantial: namely, $2.42 \%$ and $9.17 \%$ of households had their homes fully and half destroyed, respectively. Turning to the control group, the control municipalities experienced very little to no damage due to the earthquake.

To identify the causal effect of volunteering, it is important that the treatment and control municipalities had similar characteristics prior to the earthquake. The pre-earthquake characteristics of the two groups presented in panel A of Table 2 indicate that there is no important difference in sex and age compositions, the divorce rate and the widowed rate. Although treated municipalities display higher in- and out-migration rates, the rates are not significantly different between the two groups prior to the earthquake. However, concerns related to migration still remain. For example, individuals who are particularly health conscious in the treatment group may have moved out after

\footnotetext{
${ }^{7} \mathrm{~A}$ municipality recorded above the 75 th percentile value of the distribution of a death measure is classified as a severely damaged municipality. The death measure corresponds to the number of deaths caused by the earthquake, such as death by crushing. Refer to footnote 11 for results using different definitions of severely damaged municipalities, corresponding to results using different sampled municipalities.

${ }^{8}$ As of 1995 , approximately $98 \%$ of displaced persons, $99 \%$ of the hospitals and clinics that were closed, and $91 \%$ of public expenditure on disaster relief were concentrated in the omitted municipalities.

${ }^{9}$ Section 6 will explicitly account for housing capacity, healthcare capacity, and the provision of public resources as robustness checks.
} 
the earthquake in search of better medical facilities. The different migration patterns would bias the results if the patterns were correlated with mortality risk and differed between the two groups. Comparing in- and out-migration rates after the earthquake, however, reveals that neither inflow nor outflow rates were significantly different between the two groups. Nevertheless, one may still be concerned that individuals with a high risk of mortality, such as the elderly, moved out from the treatment group, for example, to live in nursing homes. Unfortunately, due to data limitations, it is not possible to further decompose migration rates by mortality risk. However, if the migration patterns were correlated with mortality risk, the migration would have altered the compositions of mortality risk between the two groups. To examine this possibility, I use age as a proxy for mortality risk and test the null hypotheses of equality of the percentages of individuals in their $50 \mathrm{~s}, 60 \mathrm{~s}, 70 \mathrm{~s}$, and $80 \mathrm{~s}$ or older, respectively, between the two groups. The null hypothesis is not rejected for any age band for both before and after the earthquake, meaning that the results do not support the possibility that different migration patterns altered the compositions of mortality risk in the two groups. Panels B and C of Table 2 further present pre-earthquake characteristics related to education and economy by treatment status, for which I did not find any significant difference between the two groups.

The identification of the effect of volunteering on mortality also requires that trends in the treatment and control groups were the same prior to the earthquake. Figure 4 plots the mortality rate by age cohort. The mortality rate is expressed per 1,000 individuals in the corresponding age cohort. For a comparison purpose, the mortality rate of the set of municipalities that recorded a positive level of earthquake damage, including severely damaged municipalities, is also reported. Not surprisingly, Fig. 4 shows sharp spikes in the year of the earthquake, 1995, regardless of age cohort for the set of damaged municipalities. As expected, however, after excluding the severely damaged municipalities from the sample, the treatment group does no longer exhibit the sharp spikes in 1995. Prior to the earthquake, the mortality rates between the treatment and control groups exhibited downward trends in every age cohort with higher mortality rates in the treatment group for individuals in their 50s to $70 \mathrm{~s}$. Note that the higher pre-earthquake mortality rates do not invalidate the identification because the systematic differences between the two groups are absorbed by municipality fixed effects in specification (1). After the earthquake, although the mortality rates observed in the treatment group remain higher, the gaps in the mortality rates between the two groups narrowed for both individuals in their 60s and 70s, implying that the mortality rates of the treatment group decreased to a greater extent relative to the control group. Turning to individuals in their 80s or older, the pre-earthquake trends in mortality between the two groups were very similar. After the earthquake, the treatment group appears to have experienced a greater reduction in the mortality rates, which is in line with the possibility that an increase in volunteering as a result of the earthquake reduced the mortality rates of this age cohort.

\section{Data and variables}

My sample consists of observations for 84 municipalities in Hyogo Prefecture from 1990 to 2000. Data on volunteering are available from the Hyogo Council of Social Welfare Activity Report 
(Kennai Syakyo Katsudo Genkyo Chosa 1991 - 2001). The report provides various figures related to volunteering, such as the number of volunteers at the municipality level. Details of the manner in which volunteers are registered with the council can be found in Appendix 2. I also extract data on volunteer characteristics, such as age and occupation, and the contents and frequency of voluntary work from the Report on the Trend in Volunteer Activity (Volunteer Katsudo Doko Chosa Hokokusyo 1997), which is a report on a survey of volunteering in Hyogo Prefecture that has been conducted every four years since 1984 .

Information on the physical damage due to the earthquake was provided by the Disaster Prevention Division of Hyogo Prefecture. The document reports physical damage due to the earthquake officially confirmed by the Ministry of Internal Affairs and Communications. Earthquake damage is categorized into injuries, deaths, and damage to buildings, and each category is further divided into sub-categories according to the extent of the damage.

Data on mortality and divorce are obtained from the Current Population Survey Report (Jinko Dotai Chosa 1990 - 2000) conducted every year by the Ministry of Health, Labour, and Welfare. The survey has been conducted since 1898 and collects data on births, deaths, stillbirths, marriages, and divorces. Public medical expenditures on the elderly are obtained from the National Health Insurance and Health Insurance for the Aged in Hyogo (Hyogo no Kokuho Rouken 1991 - 2001). The document summarizes public expenditures related to health at the municipality level. Information on donations of money to charity was provided by the Hyogo branch of the Japanese Red Cross. The data is on money donated to the Japanese Red Cross and is available from 1989 onwards. Information on temporary housing for earthquake victims are available from the Department of Land Development (2000) of Hyogo Prefecture.

Data on covariates other than variables listed above are obtained from a survey report, the System of Social and Demographic Statistics of Japan (Syakai Jinko Tokei Taikei 1990 - 2000). The survey has been conducted since 1976 and collects information on socio-economic and demographic conditions of municipalities. As socio-economic indicators, I use municipality level measures of economic activity, demography, healthcare expenditure, and educational level: taxable income per capita, unemployment rate, sex ratio, age-cohort-specific population, divorce rate, medical expenditures on the elderly per capita, and high school participation rate. The first lag of population is used because mortality and population in period $t$ are simultaneously determined. Data on the unemployment rate and population by age cohort are available only in census years (i.e., 1990, 1995, and 2000). Thus, values in years other than census years are computed in a manner detailed in Appendix 3.

\section{Results}

I begin by presenting the OLS estimates of eq. (1) in Table 3. The dependent variables in columns (1), (3), (5), and (7) correspond to the log of the number of individuals who died in their 50s, 60s, 70s, and 80 s or older, respectively, and each column controls for municipality and year fixed effects. Adjacent even-numbered columns further control for time varying municipality characteristics. Table 3 indicates that every coefficient estimate is not significantly different from zero, implying 
that volunteering had no significant effect on mortality in any age cohort. The OLS estimator is, however, biased if (i) unobserved heterogeneity across municipalities that affects mortality is also correlated with the number of volunteers or (ii) the levels of mortality and volunteering are simultaneously determined. To address the possible endogeneity of volunteering, eq. (1) is estimated using the IV estimator.

Table 4 presents the first-stage and reduced-form estimates of the effect of earthquake damage on volunteering and on age-cohort-specific mortality, respectively, and the IV estimates of the effect of volunteering on mortality (i.e., $\beta_{1}$ in eq. (1)). Panels A and B present results using the base sample that consists of the treatment and control groups. In addition, for a comparison purpose, panel $\mathrm{C}$ presents results using the full sample that consists of the treatment group, the control group and severely damaged municipalities. Earthquake damage is measured by percentage of individuals slightly injured, although other damage indicators will also be used as robustness checks. The damage indicator is equal to zero in every municipality before the earthquake and takes a positive value, for example 10, throughout the post-earthquake period if ten percent of the population is slightly injured in a municipality.

Panel A corresponds to a specification that controls only for municipality and year fixed effects. The first-stage estimates presented in column (1) indicate that earthquake damage had positive effects on volunteering, and the effects are highly statistically significant. Panel A is, however, not correctly specified if any difference across municipalities that varies over time affects mortality. To account for time varying heterogeneity across municipalities that may affect mortality, socio-economic indicators are added in panel B. The results are robust to the inclusion of additional controls, and indicate that a one-percentage-point increase in the percentage of individuals slightly injured raised the number of volunteers by approximately $20 \%$ on average. Using the full sample yields qualitatively similar first-stage results (panel C, column (1)). It is important for the identification that the instrument is not weak, meaning that the instrument and the level of volunteering are highly correlated. A weak instrument is known to bias the IV estimator toward the probability limit of the corresponding OLS estimator. Stock et al. (2002) compute the critical value for the weak instrument test based on the first-stage F-statistic and suggest that an F-statistic above approximately 10 makes IV inferences reliable. Note in this regard that the F-statistics on the excluded instrument reported in column (2) exceed 10. Thus, according to their test for weak instruments, the instrument is not weak.

The reduced-form estimates in column (3) of each panel show that a higher rate of earthquake damage was significantly associated with lower mortality rates of people in their 70s and 80s or older. Finally, the causal effect of interest reported in column (4) of each panel indicates that volunteering had no significant effect on the mortality of people in their 50s and 60s, while it significantly reduced the mortality among people in their 70 s and 80 s or older. ${ }^{10}$ Of particular

\footnotetext{
${ }^{10}$ As mentioned in Section 2, the measure of volunteering does not capture volunteers not registered with and not known to the Hyogo Council of Social Welfare. The presence of the unregistered and unknown volunteers can affect the results in Table 4 if (and only if) the propensity to register or to be recognized by the council was correlated with elderly mortality and differed between the treatment and control groups. Due to data limitation, it is impossible to further investigate this possibility. However, it is worth noting that the presence of the unregistered and unknown volunteers does not invalidate the story that volunteers reduced elderly mortality, although it affects the interpretation
} 
note, the point estimates obtained using the base sample (panel B, column (4)) are not significantly different from corresponding estimates obtained using the full sample (panel C, column (4)), ${ }^{11}$ which has important implications regarding a concern of selective mortality. Recall that one of the reasons to omit severely damaged municipalities that account for the vast majority of fatalities due to the earthquake is to address a concern that the earthquake selectively killed vulnerable individuals, leading to a lower mortality rate afterwards because only fit people survived. If this is the case, both IV and reduced-form estimates obtained using the full sample would be greater (in absolute terms) than corresponding estimates from the base sample, because the full sample contains, in addition to individuals in the treatment group, those who were exceptionally fit and survived despite the fact that they were in the severely damaged municipalities. However, although the IV and reduced-form estimates obtained from the full sample are generally greater (in absolute terms), the estimates obtained from the two alternative sample specifications are not significantly different from each other, implying that the earthquake is unlikely to have disproportionately killed vulnerable individuals within each age band. This is not surprising, as the vast majority of victims were crushed or choked to death due to the collapse of their homes and passed away within 24 hours after the earthquake occurred (Hyogo Prefecture, 2005). ${ }^{12}$ Thus, the initial health endowments of victims within each age band may have not been particularly important for survival, unlike deaths due to, for example, hunger for which people with greater initial health endowments are more likely to survive.

The estimated causal effect suggests that a one-percent increase in the number of volunteers reduced mortality among people in their 70 s and 80 s or older by approximately $0.09 \%$ and $0.15 \%$, respectively, on average (column (4), panel B). Evaluated at the mean, the estimates imply that the lives of roughly two individuals aged 70 or older (out of 199 persons) were saved in a given year when the number of volunteers increased by 100 (out of 1,389 persons). Conditional on living until 70, a one-year extension of life is a substantial increase, corresponding to an approximately six percent increase in life expectancy. ${ }^{13}$ Having estimated the elasticity of mortality with respect to the number of volunteers, it is informative to know the number of hours of voluntary work to assess the size of the estimated elasticity. Unfortunately, data on the intensity of voluntary work are very limited. Nevertheless, using data on frequency and contents of voluntary work, I compute the number of hours worked per volunteer (see Appendix 6). The estimate indicates that a volunteer worked approximately 88 hours per annum, implying that 100 additional volunteers correspond to roughly 8,800 hours of labour. To assess the economic value of 8,800 volunteer hours, I assign, to these volunteer hours, how much it would have cost to hire paid workers to do the same work that volunteers did without payment, as recommended in the manual on the measurement of volunteer work (International Labour Office, 2011). Following the calculations in Appendix 6, 8,800 hours

\footnotetext{
of the estimates.

${ }^{11}$ In addition to the full sample, I also run regressions using the samples without the one to five most severely damaged municipalities. The results are robust to changes in sample specifications, confirming that the mortality of individuals in their 70s and 80 s or older decreased following an increase in the number of volunteers as a result of earthquake shocks (see Appendix 4).

${ }^{12}$ The earthquake occurred at 5:46 in the morning, and most victims died at home.

${ }^{13}$ Life expectancy at age 70 in Hyogo Prefecture was 16 years in 2000. The calculation of life expectancy can be found in Appendix 5.
} 
of labour are worth $\$ 71,360$, implying that approximately $\$ 71,360$ worth of labour was used to save the lives of two individuals aged 70 or older in a given year. ${ }^{14}$

As the estimates capture the net effect of volunteering on mortality, it cannot be determined whether the reduction in mortality is driven by that of volunteers or care recipients. However, the reduction in mortality among people in their 80s or older occurred among care recipients because every volunteer was younger than 80 (Hyogo Council of Social Welfare, 1997). The effect on people in their $70 \mathrm{~s}$ is inconclusive given that $13 \%$ of volunteers are in their $70 \mathrm{~s}$. It is, however, likely that the reduction in mortality occurred among care recipients because volunteers are presumably fitter than care recipients. This inference is further strengthened by the fact that volunteering had no significant effect on the mortality of people in their 50s and 60s. As roughly half of volunteers were in their 50s or $60 \mathrm{~s}$, a reduction in mortality of people in these age cohorts would be observed if volunteering reduced the mortality of volunteers themselves. ${ }^{15}$

It has been established that volunteering reduced mortality among the elderly. However, the results are not informative regarding the mechanisms through which volunteering affects mortality. To infer the operating mechanisms, I regress cause-specific mortality on volunteering. ${ }^{16}$ Although it is at best suggestive evidence, examining the types of deaths affected by volunteering would help narrow down the potential operating mechanisms. Several possible channels are discussed below. Firstly, it may be the case that volunteering enhances social contact, and more social contact subsequently leads to better health and reduced mortality risk (House et al., 1988). Companionship of volunteers may encourage positive emotions, such as happiness and a sense of security, which serves to reduce stressors and thereby improve the health status of an individual. The link between stressors and health status is well documented. For example, Kiecolt-Glaser and Glaser (1995) find evidence that stressors affect the strength of the immune system, which in turn influences the progression of cancer and infectious diseases. Secondly, using volunteer services means that someone visits the elderly regularly, implying that the elderly are provided with substantial care. Recalling that some of the main activities of volunteers are to provide meals and assistance with daily tasks including going out, volunteers may help the elderly to have well-balanced meals and/or engage in exercise, which may subsequently improve their general health conditions.

Table 5 reports the IV estimates of the effect of volunteering on cause-specific mortality after controlling for socio-economic indicators and municipality and year fixed effects. Columns (1) to (3) indicate that volunteering significantly reduced mortality caused by cerebral vascular disease, heart disease, and decrepitude. Risks of cerebral vascular disease and heart disease are known to

\footnotetext{
${ }^{14}$ The estimates in Table 4 capture the contemporaneous effect of volunteering on mortality; therefore, they reflect the short-run effect of volunteering. Long-run effects, if any, are not included in calculations.

${ }^{15}$ Table 4 indicates that the short-run mortality of individuals in their $50 \mathrm{~s}$ and $60 \mathrm{~s}$ is not affected by voluntary work. This does not exclude the possibility that volunteering affects the mortality of those in their 50s and 60s later in life. For example, Harris and Thoresen (2005), using data on elderly Americans, find lower mortality risk among volunteers relative to non-volunteers.

${ }^{16}$ A caveat is that data on mortality by cause of death are available by municipality but not by age. As types of mortality prevalent among younger individuals, such as those related to childbirth or suicide, are irrelevant to my analysis, I run regressions only on types of mortality prevalent among individuals in their 70s or older, the age cohort for which significant effects of volunteering on mortality are found. The proportions of deaths accounted for by individuals in their 70s or older are as follows: cerebral vascular disease (80\%), heart disease (79\%), decrepitude (100\%), cancer (58\%), hypertensive disease (89\%), and pneumonia (90\%).
} 
be reduced by a healthy diet and regular exercise. Thus, volunteering may have reduced mortality caused by these diseases by improving the general health conditions of the elderly by, for example, providing them with well-balanced meals or helping them engage in exercise. Likewise, the significant reduction in mortality caused by decrepitude (i.e., natural death due to age with no particular known disease cause) was also likely due to an improvement in general health conditions.

Mortality caused by illnesses documented to be affected by improvement in the strength of the immune system, such as cancer and infectious diseases (e.g., pneumonia), was not affected by volunteering (columns (4) and (5)). The results imply that the reduced stress channel is unlikely to be an operating mechanism. ${ }^{17}$ Column (6) indicates that volunteering also had no statistically significant effects on hypertensive disease, which can be caused by, among other factors, stress, congenital defects, malnutrition, and obesity. Volunteering could reduce elderly mortality caused by hypertensive disease, possibly through improving the nutritional status or reducing the stress of the elderly. However, the level of mortality due to hypertensive disease is very low. Thus, there may not be sufficient variation in the data set to precisely estimate the effect on the mortality caused by hypertensive disease.

\section{Robustness checks}

In this section, to establish that the main results are not driven by unobserved factors correlated with volunteering that reduce mortality, such as general altruism, I firstly control for their proxy and also conduct falsification exercises. Secondly, I investigate whether the main findings in the previous section are driven by omitting relevant variables, such as public spending on disaster relief. Thirdly, further falsification exercises are conducted to ensure that the observed increase in volunteering is not spurious. The results for these falsification exercises are summarized in Appendix 7. Finally, I examine the robustness of the results to different damage measures as instruments, for which results are discussed in Appendix 8.

Firstly, unobserved factors apart from volunteering, such as general altruism and social cohesion, may have changed in the wake of the earthquake, and these factors, plausibly correlated with the level of volunteering, can provide alternative explanations for the previous findings. To address this concern, two strategies are employed. Firstly, I control for general altruism proxied by donations of money to charity. The inclusion of this variable would disentangle the effect of unpaid labour from that of general altruism. Results are summarized in panel A1 of Table 6. Panel A1 indicates that the first-stage and IV estimates are not sensitive to the inclusion of the proxy of general altruism: earthquake damage significantly raised the level of volunteering, which subsequently reduced the mortality of individuals in their 70s and 80s or older. The estimates of coefficients on the proxy of general altruism (not reported) are not significantly different from zero at any conventional significance level, indicating that general altruism is unlikely to have reduced mortality. Secondly, the mortality of children and young adults is regressed on volunteering. If unobserved factors such as those mentioned above drive the main results, they would also affect

\footnotetext{
${ }^{17}$ Insignificant effects on mortality caused by cancer and pneumonia in the short run do not exclude the possibility that volunteering affects mortality caused by these diseases in the longer term.
} 
the mortality of age bands other than the elderly. In contrast, if it is indeed volunteering that drives the main results, it would not affect the mortality of children and young adults as the volunteering in question targets the elderly. Panel B of Table 6 regresses the mortality of four different age bands, 0 - 9 to 30 - 39, on volunteering. Panel B indicates that the first-stage estimates are highly statistically significant, while there was no significant effect of volunteering on the mortality of children and young adults.

Secondly, one may be concerned that the main results are driven by a change in the provision of public resources subsequent to the earthquake. For example, government spending increased in the treatment municipalities after the earthquake, and some of this increased spending may have been used to construct new homes for earthquake victims or allocated to the healthcare sector. Mortality in the treatment municipalities may have decreased because treatment municipalities benefited from an improvement in living conditions and/or healthcare capacity (e.g., more healthcare professionals). These concerns are likely to be (at least partly) addressed by omitting the severely damaged municipalities because a significant proportion of public spending on disaster relief was used for the omitted municipalities. In addition, public medical expenditures that specifically target the elderly have already been controlled for in every regression. Nevertheless, to confirm that the main findings are not driven by omitting relevant variables correlated with volunteering, I control for housing capacity, measured by the number of temporary housing for earthquake victims per 100 households; healthcare capacity, measured by the number of hospitals and clinics per 1,000 individuals; and public resources, captured by a dummy variable that equals one if a municipality was located in the areas where disaster relief act was applied, and zero otherwise. ${ }^{18}$ The act was applied to the areas where the government defined to be damaged and these areas were targeted for providing various public support. Panel A2 of Table 6 reports coefficient estimates for eq. (1) with the additional control for public resources. The results are robust to the inclusion of this additional control as well as the measures of housing and healthcare capacity (see Appendix 9).

\section{Conclusion}

This paper explored the causal effect of the voluntary contributions of labour to local services, in the form of voluntary provision of daily care to the elderly, on elderly mortality. To identify the causal effect on mortality, I exploit exogenous variation in volunteering caused by an earthquake. To address the obvious issue that the earthquake increased mortality, the year of the earthquake is excluded from the sample, and only the municipalities that recorded no or little loss of life due to the earthquake are retained in the sample. Consistent with the random nature of the earthquake, no significant difference between the treatment and control municipalities was observed regarding municipality characteristics. However, a sharp increase in the level of contributions was observed after the earthquake only in the treatment municipalities. The reduced-form estimates of the effect

\footnotetext{
${ }^{18}$ Volunteering is a substitute for public resources if voluntary work crowds out public resources, while it is a complement to public resources if it fills gaps in local public resources. Omitting public resources can bias the results in Table 4 if they are correlated with volunteering and affect elderly mortality, irrespective of whether public resources complement or substitute volunteering.
} 
of the earthquake on mortality indicate that the earthquake damage significantly reduced the mortality of persons in two age cohorts, namely, those in their 70s and 80s or older. In line with these reduced-form estimates, the IV estimates indicate that volunteering significantly reduced the mortality of these same age cohorts. Regarding mechanisms, supplementary regressions suggest that volunteering likely reduced elderly mortality by improving the health conditions of the elderly.

My estimates capture the effect of volunteer work on one of a number of possible outcomes. There could also be other effects of volunteer work, such as enhancing subjective well-being or quality of life, which are important possible measures to be investigated in future research. It is also important to note that the estimates of the effect of volunteering in this paper are obtained using variation in volunteering caused by earthquake shocks. Similar to the findings in this paper, Vollhardt and Staub (2011) find that individuals who experienced adverse life events, including natural disasters, are more likely to volunteer. However, literature in this field is scarce and whether different types of disasters have the same effects on volunteering and thus whether another instrument yields similar results are still open to question.

The findings in this paper suggest that governments facing population ageing can consider encouraging voluntary work for the elderly as a method of providing support for the elderly and managing workloads in the healthcare sector. To the extent that volunteering to aid the elderly improves the health conditions of the care recipients, it can help mitigate an increase in public health spending. Moreover, aside from helping the elderly, volunteers may improve the efficiency of the healthcare sector by freeing up the time of more formally trained (paid) workers, such as social workers and healthcare assistants, who can then reallocate their time to perform tasks requiring their special skills. Given the wide variety of voluntary work being conducted, it appears crucial for more studies to be conducted to explore potential outcomes of various types of volunteer work.

\section{Supplementary material}

Supplementary material (the Appendix and Data files) is available online at the OUP website.

\section{Funding}

This work was supported by the University of Warwick Economics Department.

\section{Acknowledgments}

I am grateful to Fabian Waldinger for his constant support and guidance, and Wiji Arulampalam and Eric Strobl for the valuable comments on earlier drafts. I also received valuable comments from the editor, Francis J Teal, and two anonymous reviewers. I would like to thank Sascha O. Becker, Sonia Bhalotra, Hidehiko Ichimura, Victor Lavy, Rocco Macchiavello, Catia Montagna, Robin Naylor, Katherine Swartz, Heidi Williams, Christopher Woodruff and the participants of the EEA/ESEM Congress in Malaga, the IZA/CEPR Symposium in Ammersee, the Scottish Economic Society Conference in Perth, the ESPE Conference in Aarhus, and seminars and workshops 
at the Universities of Aberdeen, Brunel, Edinburgh, Newcastle, Stirling and Warwick for discussions that improved this paper. All remaining errors are my responsibility.

\section{References}

Andreoni, J. (1989). Giving with impure altruism: applications to charity and Ricardian equivalence. Journal of Political Economy 97:1447-1458.

Becchetti, L., Conzo, P. and Romeo, A. (2014). Violence, trust, and trustworthiness: evidence from a nairobi slum. Oxford Economic Papers 66:283-305.

Becker, G.S. (1974). A theory of social interactions. Journal of Political Economy 82:1063-1093.

Carlsson, F., Johansson-Stenman, O. and Khanh Nam, P. (2015). Funding a new bridge in rural Vietnam: a field experiment on social influence and default contributions. Oxford Economic Papers 67:987-1014.

Charities Aid Foundation (2014). World giving index 2014: A global view of giving trends. Tech. rep., Charities Aid Foundation, Kent.

DellaVigna, S., List, J.A. and Malmendier, U. (2012). Testing for atruism and social pressure in charitable giving. The Quarterly Journal of Economics 127:1-56.

Department of Land Development (2000). Record of temporary housing following the Kobe earthquake. Kobe: Hyogo Prefecture.

Duncan, B. (1999). Modeling charitable contributions of time and money. Journal of Public Economics 72:213 - 242.

Edgington, D.W. (2010). Reconstructing Kobe: The geography of crisis and opportunity. Vancouver: University of British Columbia Press.

Fire and Disaster Management Agency (2006). Final report on the great Hanshin-Awaji earthquake. URL: http://www.fdma.go.jp/data/010604191452374961.pdf, Accessed: 01/12/07.

Fire Service and Disaster Prevention Division (1996). The great Hanshin-Awaji earthquake record of Hyogo Prefecture over a year. Kobe: Hyogo Prefecture.

Freeman, R.B. (1997). Working for nothing: the supply of volunteer labor. Journal of Labor Economics 15:140-66.

Harris, A.H.S. and Thoresen, C.E. (2005). Volunteering is associated with delayed mortality in older people: analysis of the longitudinal study of aging. Journal of Health Psychology 10:739752. 
House, J.S., Landis, K.R. and Umberson, D. (1988). Social relationships and health. Science 241:540-545.

Hyogo Council of Social Welfare (1997). Report on the trend in volunteer activity. Tech. rep., Hyogo Council of Social Welfare, Kobe.

Hyogo Prefecture (2005). Survey on the death toll from the great Hanshin-Awaji earthquake. URL: https://web.pref.hyogo.lg.jp/pa20/pa20_000000016.html, Accessed: 01/05/13.

International Labour Office (2011). Manual on the measurement of volunteer work. Geneva: International Labour Office.

Kiecolt-Glaser, J.K. and Glaser, R. (1995). Psychoneuroimmunology and health consequences: data and shared mechanisms. Psychosomatic Medicine 57:269-274.

Meier, S. and Stutzer, A. (2008). Is volunteering rewarding in itself? Economica 75:39-59.

Stock, J.H., Wright, J.H. and Yogo, M. (2002). A survey of weak instruments and weak identification in generalized method of moments. Journal of Business \& Economic Statistics 20:518-29.

Suga, M. (2011). Logic of and systems for volunteer disaster relief activities in japan: current situations and challenges 15 years after the 1995 Great Hanshin-Awaji earthquake. Journal of Disaster Research 6:236-243.

United Nations Centre for Regional Development (1995). A call to arms: report of the 17 January 1995 great Hanshin earthquake. UNCRD discussion paper, UNCRD, Nagoya.

Vollhardt, J.R. and Staub, E. (2011). Inclusive altruism born of suffering: the relationship between adversity and prosocial attitudes and behavior toward disadvantaged outgroups. American Journal of Orthopsychiatry 81:307-15. 


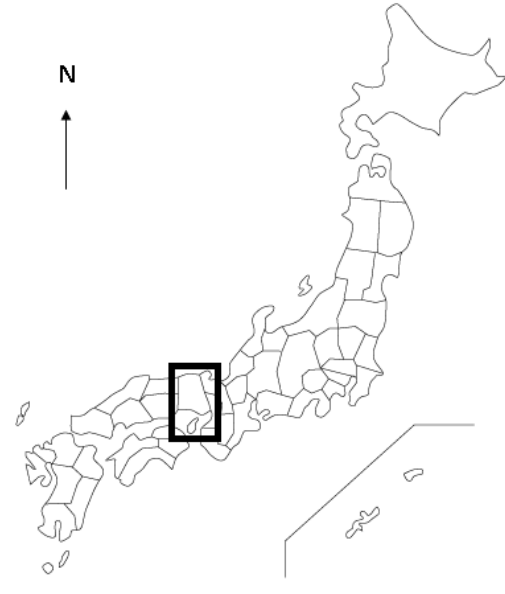

A. Hyogo Prefecture

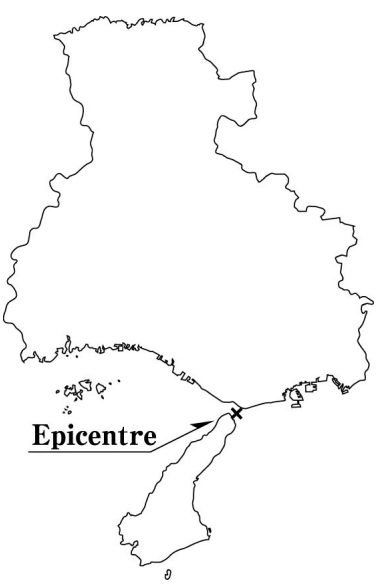

B. The epicentre

Notes: Panel A indicates the location of Hyogo Prefecture. Panel B shows the location of the epicentre within Hyogo Prefecture.

Fig. 1. Hyogo Prefecture and the epicentre

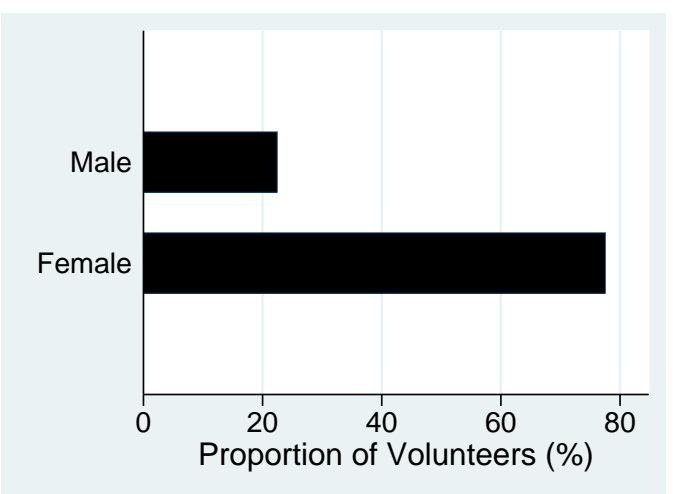

A. Sex

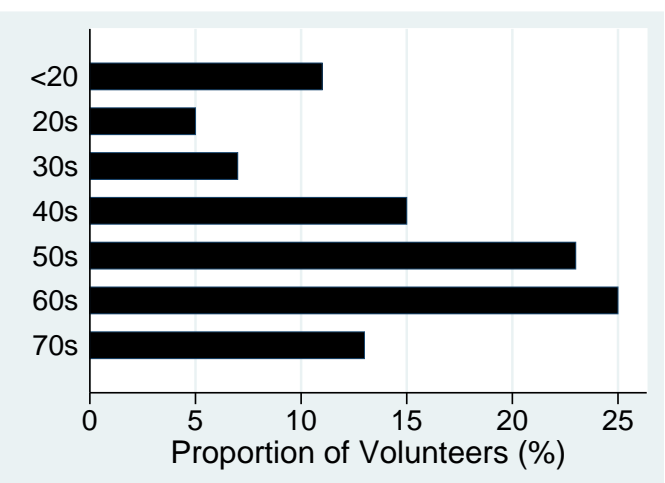

B. Age

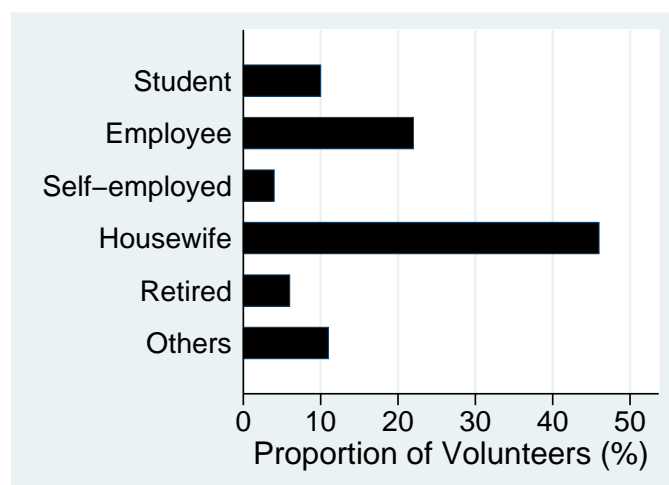

C. Occupation

Fig. 2. Volunteer characteristics 


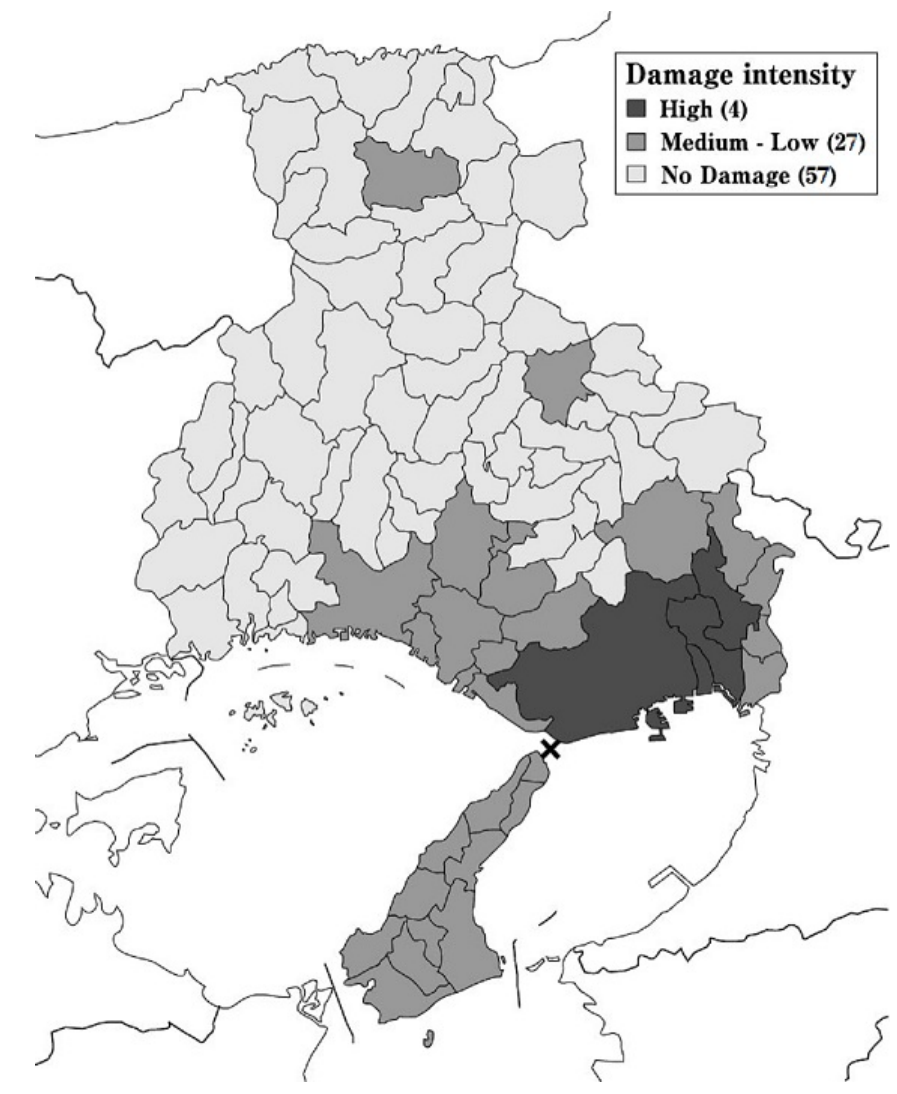

Notes: The black area is a subset of municipalities severely damaged by the earthquake and excluded from the sample. The dark grey area corresponds to the treatment group that recorded little to moderate damage, while the light grey area corresponds to the control group that is not hit by the earthquake.

Fig. 3. Sampled and omitted municipalities 


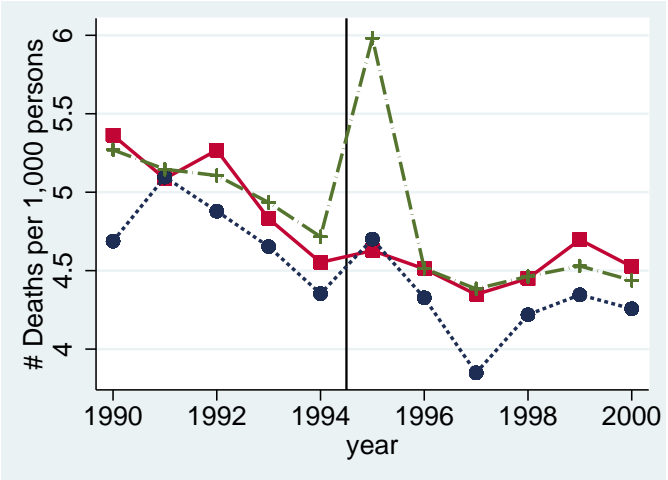

A. Mortality Rate, 50s

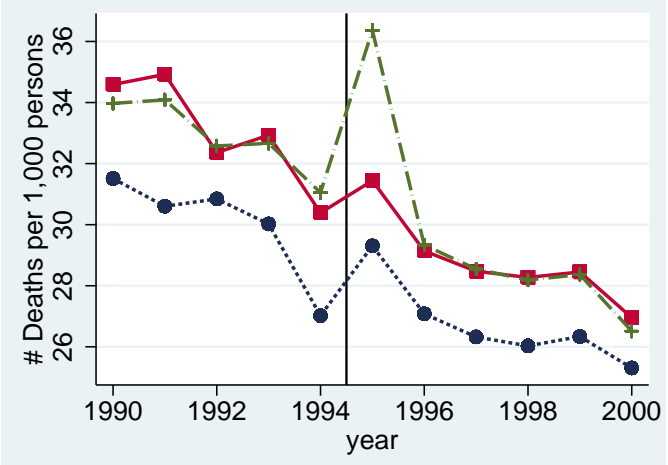

C. Mortality Rate, 70 s

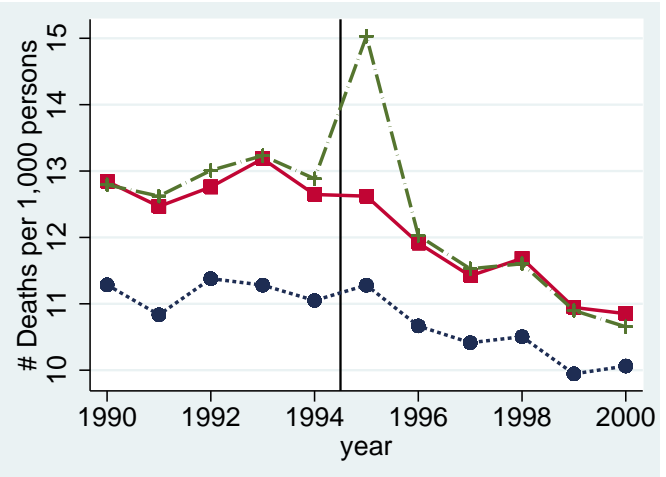

B. Mortality Rate, 60s

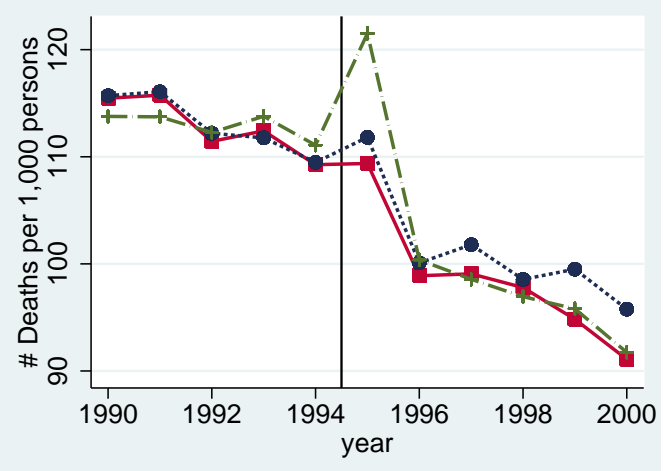

D. Mortality Rate, $80+$

Treatment

Control

-.+. - Damaged Municipalities

Notes: Each series represents the weighted average number of deaths per 1,000 persons. Weights are the population in the corresponding age cohort.

Fig. 4. Mortality rate by age cohort 
Table 1. Earthquake damage

\begin{tabular}{|c|c|c|c|c|}
\hline & \multicolumn{2}{|c|}{ Treatment } & \multicolumn{2}{|c|}{ Control } \\
\hline & \multicolumn{2}{|c|}{27 municipalities } & \multicolumn{2}{|c|}{57 municipalities } \\
\hline & Mean & Std. Err. & Mean & Std. Err. \\
\hline$\%$ Deaths & 0.01 & 0.15 & 0.00 & 0.00 \\
\hline$\%$ Serious injuries & 0.06 & 0.49 & 0.00 & 0.01 \\
\hline$\%$ Minor injuries & 0.49 & 1.34 & 0.00 & 0.00 \\
\hline$\%$ Fully destroyed households & 2.42 & 2.96 & 0.00 & 0.03 \\
\hline$\%$ Half destroyed households & 9.17 & 5.55 & 0.01 & 0.11 \\
\hline
\end{tabular}

Notes: Mean refers to weighted means where weights are population. Variable labels indicate the following: percentage of individuals who died, percentage of individuals seriously injured, percentage of individuals slightly injured, percentage of households whose homes were fully destroyed, and percentage of households whose homes were half destroyed. 
Table 2. Municipality characteristics

\begin{tabular}{|c|c|c|c|c|c|}
\hline & \multicolumn{2}{|c|}{ Treatment } & \multicolumn{2}{|c|}{ Control } & \multirow[b]{3}{*}{ p-value } \\
\hline & \multicolumn{2}{|c|}{27 municipalities } & \multicolumn{2}{|c|}{57 municipalities } & \\
\hline & Mean & Std. Err. & Mean & Std. Err. & \\
\hline \multicolumn{6}{|l|}{ A. Demography } \\
\hline Sex ratio & 0.97 & 0.12 & 0.93 & 0.04 & 0.77 \\
\hline$\%$ Pop in their 50s & 12.78 & 6.42 & 12.69 & 4.41 & 0.99 \\
\hline$\%$ Pop in their $60 \mathrm{~s}$ & 8.94 & 5.49 & 11.51 & 4.23 & 0.72 \\
\hline$\%$ Pop in their $70 \mathrm{~s}$ & 5.18 & 4.27 & 7.17 & 3.42 & 0.73 \\
\hline$\%$ Pop in their 80 s+ & 2.22 & 2.83 & 3.42 & 2.41 & 0.76 \\
\hline$\%$ Divorced & 2.45 & 2.97 & 1.77 & 1.74 & 0.83 \\
\hline$\%$ Widowed & 7.40 & 5.04 & 10.06 & 3.98 & 0.69 \\
\hline In-migration per 1,000 persons & 45.92 & 18.01 & 33.24 & 10.62 & 0.52 \\
\hline Out-migration per 1,000 persons & 44.88 & 17.82 & 34.87 & 10.87 & 0.62 \\
\hline \multicolumn{6}{|l|}{ B. Education } \\
\hline$\%$ Compulsory & 22.48 & 8.03 & 31.17 & 6.13 & 0.41 \\
\hline$\%$ High school & 33.44 & 9.08 & 30.36 & 6.09 & 0.78 \\
\hline$\%$ University & 14.93 & 6.86 & 10.22 & 4.01 & 0.53 \\
\hline \multicolumn{6}{|l|}{ C. Economy } \\
\hline \% Unemployed & 1.68 & 2.47 & 1.23 & 1.46 & 0.87 \\
\hline$\%$ Employed & 47.45 & 9.61 & 48.09 & 6.62 & 0.96 \\
\hline Per capita income & 1402.3 & 179.0 & 1134.3 & 59.9 & 0.08 \\
\hline Per capita medical expenditure & 637.3 & 85.0 & 519.7 & 26.8 & 0.09 \\
\hline
\end{tabular}

Notes: Mean refers to weighted means where weights are population. Figures are the average over the preearthquake period (i.e., year $<1995$ ) except for the variables that are available only in census years for which the averages in 1990 are reported. The p-value corresponds to p-values of tests under the null hypotheses of equality of means or proportions between the treatment and control groups. The sex ratio corresponds to the number of males relative to females. \% Divorced and \% Widowed are defined for individuals aged 15 or above. Per capita taxable income and public medical expenditures on the elderly are measured in $¥ 1,000$. 
Table 3. Effect of volunteering on mortality (OLS estimates)

\begin{tabular}{lcccccccc}
\hline \hline \multirow{2}{*}{ Dependent variable: } & \multicolumn{2}{c}{ \# Deaths in 50s } & \# Deaths in 60s & \# Deaths in 70s & \# Deaths in 80+ \\
\cline { 2 - 9 } & $(1)$ & $(2)$ & $(3)$ & $(4)$ & $(5)$ & $(6)$ & $(7)$ & $(8)$ \\
\hline & -0.013 & -0.023 & 0.017 & 0.013 & 0.006 & 0.007 & -0.009 & -0.008 \\
& $(0.023)$ & $(0.023)$ & $(0.012)$ & $(0.013)$ & $(0.011)$ & $(0.011)$ & $(0.011)$ & $(0.011)$ \\
\hline Controls & no & yes & no & yes & no & yes & no & yes \\
Municipality FE & yes & yes & yes & yes & yes & yes & yes & yes \\
Year FE & yes & yes & yes & yes & yes & yes & yes & yes \\
\hline
\end{tabular}

Notes: Standard errors are clustered by municipality. The dependent variable is the number of age-cohort specific deaths. Controls included in the analysis are income per capita, unemployment rate, sex ratio, age-cohort-specific population, divorce rate, medical expenditures on the elderly per capita, high school participation rate, and municipality and year fixed effects. Each variable in level is in log. Due to one missing value in the number of volunteers, the sample size is $839=(84$ municipalities $\times 10$ years $)-1$. 
Table 4. First-stage, reduced-form, and IV estimates of mortality regressions

\begin{tabular}{|c|c|c|c|c|c|}
\hline \multirow[t]{2}{*}{ Dependent variable: } & & \multirow{2}{*}{$\begin{array}{l}\text { Volunteer } \\
\text { First-stage }\end{array}$} & \multirow[b]{2}{*}{ F-statistic } & \multicolumn{2}{|c|}{ Mortality by age cohort } \\
\hline & & & & Reduced-form & IV \\
\hline Sample & Controls & (1) & (2) & (3) & (4) \\
\hline \multicolumn{6}{|l|}{ A. Base sample } \\
\hline A1. \# Deaths in 50s & no & $\begin{array}{c}0.210 * * * \\
(0.042)\end{array}$ & 25.1 & $\begin{array}{c}0.013 \\
(0.015)\end{array}$ & $\begin{array}{c}0.063 \\
(0.064)\end{array}$ \\
\hline A2. \# Deaths in $60 \mathrm{~s}$ & no & $\begin{array}{c}0.215 * * * \\
(0.043)\end{array}$ & 24.7 & $\begin{array}{l}-0.003 \\
(0.007)\end{array}$ & $\begin{array}{c}-0.016 \\
(0.036)\end{array}$ \\
\hline A3. \# Deaths in $70 \mathrm{~s}$ & no & $\begin{array}{c}0.209 * * * \\
(0.041)\end{array}$ & 25.6 & $\begin{array}{c}-0.021 * * * \\
(0.008)\end{array}$ & $\begin{array}{c}-0.102 * * * \\
(0.024)\end{array}$ \\
\hline A4. \# Deaths in $80+$ & no & $\begin{array}{c}0.216 * * * \\
(0.044)\end{array}$ & 24.5 & $\begin{array}{c}-0.029 * * * \\
(0.005)\end{array}$ & $\begin{array}{c}-0.135 * * * \\
(0.046)\end{array}$ \\
\hline \multicolumn{6}{|l|}{ B. Base sample } \\
\hline B1. \# Deaths in 50s & yes & $\begin{array}{c}0.209 * * * \\
(0.039)\end{array}$ & 29.5 & $\begin{array}{l}-0.003 \\
(0.015)\end{array}$ & $\begin{array}{l}-0.014 \\
(0.071)\end{array}$ \\
\hline B2. \# Deaths in 60s & yes & $\begin{array}{c}0.217 * * * \\
(0.040)\end{array}$ & 28.8 & $\begin{array}{l}-0.000 \\
(0.009)\end{array}$ & $\begin{array}{l}-0.001 \\
(0.040)\end{array}$ \\
\hline B3. \# Deaths in 70s & yes & $\begin{array}{c}0.214 * * * \\
(0.041)\end{array}$ & 27.1 & $\begin{array}{c}-0.018^{*} \\
(0.010)\end{array}$ & $\begin{array}{c}-0.085^{* *} \\
(0.038)\end{array}$ \\
\hline B4. \# Deaths in $80+$ & yes & $\begin{array}{c}0.225 * * * \\
(0.042)\end{array}$ & 28.2 & $\begin{array}{c}-0.034 * * * \\
(0.006)\end{array}$ & $\begin{array}{c}-0.149 * * * \\
(0.042)\end{array}$ \\
\hline \multicolumn{6}{|l|}{ C. Full sample } \\
\hline C1. \# Deaths in 50s & yes & $\begin{array}{c}0.183 * * * \\
(0.033)\end{array}$ & 31.1 & $\begin{array}{l}-0.006 \\
(0.014)\end{array}$ & $\begin{array}{l}-0.031 \\
(0.079)\end{array}$ \\
\hline C2. \# Deaths in 60s & yes & $\begin{array}{c}0.191 * * * \\
(0.033)\end{array}$ & 32.5 & $\begin{array}{l}-0.008 \\
(0.011)\end{array}$ & $\begin{array}{l}-0.041 \\
(0.060)\end{array}$ \\
\hline C3. \# Deaths in 70s & yes & $\begin{array}{c}0.189 * * * \\
(0.035)\end{array}$ & 29.7 & $\begin{array}{c}-0.021 * * \\
(0.010)\end{array}$ & $\begin{array}{c}-0.111^{*} \\
(0.057)\end{array}$ \\
\hline C4. \# Deaths in $80+$ & yes & $\begin{array}{c}0.200 * * * \\
(0.036)\end{array}$ & 31.5 & $\begin{array}{c}-0.031 * * * \\
(0.007)\end{array}$ & $\begin{array}{c}-0.155^{* * * *} \\
(0.044)\end{array}$ \\
\hline
\end{tabular}

Notes: $* p<.10, * * p<.05$, and $* * * p<.01$. Standard errors are clustered by municipality. Base sample used in panels A and B consists of the treatment group (27 municipalities) and the control group (57 municipalities). In addition to these 84 municipalities, full sample used in panel $\mathrm{C}$ contains four severely damaged municipalities. First-stage and reduced-form estimates are the estimated coefficients on the damage indicator. The IV estimates are the estimates of $\beta_{1}$ in eq. (1). Refer to Table 3 for controls included in the analysis. The F-statistics on the excluded instrument are reported. 
Table 5. Effect of volunteering on mortality by cause of death (IV Estimates)

\begin{tabular}{|c|c|c|c|c|c|c|}
\hline Cause of death: & $\begin{array}{c}\text { Cerebral } \\
\text { vascular } \\
\text { disease }\end{array}$ & $\begin{array}{l}\text { Heart } \\
\text { disease }\end{array}$ & $\begin{array}{l}\text { Decrepi } \\
\text {-tude }\end{array}$ & Cancer & Pneumonia & $\begin{array}{c}\text { Hypertensive } \\
\text { disease }\end{array}$ \\
\hline \multirow[t]{3}{*}{ Mean (persons): } & 39.40 & 52.20 & 10.41 & 82.51 & 23.63 & 2.50 \\
\hline & (1) & (2) & (3) & (4) & (5) & (6) \\
\hline & $\begin{array}{c}-0.257 * * * \\
(0.072)\end{array}$ & $\begin{array}{c}-0.192 * * * \\
(0.069)\end{array}$ & $\begin{array}{c}-0.257 * * \\
(0.121)\end{array}$ & $\begin{array}{l}-0.035 \\
(0.042)\end{array}$ & $\begin{array}{l}-0.036 \\
(0.062)\end{array}$ & $\begin{array}{r}-0.072 \\
(0.096)\end{array}$ \\
\hline
\end{tabular}

Notes: $* * p<.05$ and $* * * p<.01$. Standard errors are clustered by municipality. The dependent variable is the log of the number of cause-specific deaths. The coefficient estimates on the number of volunteers in $\log$ (i.e., $\beta_{1}$ in eq. (1)) are reported. Every column controls for a full set of socio-economic indicators and municipality and year fixed effects. Refer to Table 3 for socio-economic indicators included in the analyses.

Table 6. Alternative regression specifications

\begin{tabular}{|c|c|c|c|c|}
\hline \multirow[t]{3}{*}{ Dependent variable: } & \multicolumn{2}{|c|}{ Volunteer } & \multicolumn{2}{|c|}{ Mortality by age cohort } \\
\hline & \multicolumn{2}{|c|}{ First-stage } & \multicolumn{2}{|c|}{ IV } \\
\hline & Damage & Std. err. & Volunteer & Std. err. \\
\hline \multicolumn{5}{|c|}{ A. Additional controls } \\
\hline \multicolumn{5}{|c|}{ A1. Monetary donation } \\
\hline \# Deaths in $50 \mathrm{~s}$ & $0.214 * * *$ & $(0.040)$ & -0.010 & $(0.066)$ \\
\hline \# Deaths in $60 \mathrm{~s}$ & $0.221 * * *$ & $(0.042)$ & 0.010 & $(0.041)$ \\
\hline \# Deaths in $70 \mathrm{~s}$ & $0.218 * * *$ & $(0.043)$ & $-0.078 * *$ & $(0.037)$ \\
\hline \# Deaths in $80+$ & $0.228 * * *$ & $(0.044)$ & $-0.148 * * *$ & $(0.043)$ \\
\hline \multicolumn{5}{|l|}{ A2. Public resources } \\
\hline \# Deaths in $50 \mathrm{~s}$ & $0.182 * * *$ & $(0.044)$ & 0.017 & $(0.081)$ \\
\hline \# Deaths in $60 \mathrm{~s}$ & $0.188 * * *$ & $(0.046)$ & -0.003 & $(0.045)$ \\
\hline \# Deaths in $70 \mathrm{~s}$ & $0.187 * * *$ & $(0.045)$ & $-0.074 *$ & $(0.043)$ \\
\hline \# Deaths in $80+$ & $0.197 * * *$ & $(0.050)$ & $-0.165 * * *$ & $(0.058)$ \\
\hline \multicolumn{5}{|c|}{ B. Alternative dependent variables } \\
\hline \# Deaths in 00s & $0.220 * * *$ & $(0.042)$ & -0.069 & $(0.067)$ \\
\hline \# Deaths in $10 \mathrm{~s}$ & $0.219 * * *$ & $(0.042)$ & 0.050 & $(0.057)$ \\
\hline \# Deaths in $20 \mathrm{~s}$ & $0.220 * * *$ & $(0.041)$ & 0.028 & $(0.046)$ \\
\hline \# Deaths in $30 \mathrm{~s}$ & $0.211^{* * *}$ & $(0.041)$ & -0.045 & $(0.080)$ \\
\hline
\end{tabular}

Notes: $* p<.10, * * p<.05$, and $* * * p<.01$. Standard errors are clustered by municipality. First-stage estimates are the estimated coefficients on the damage indicator. The IV estimates are the estimates of $\beta_{1}$ in eq.(1). Rows in each panel correspond to the regressions for the mortality of individuals in their 50s, $60 \mathrm{~s}, 70 \mathrm{~s}$, and 80 or older, respectively, except panel B (number of deaths in log of those in their 00s, 10s, 20s, and 30s). Refer to Table 3 for the controls included in panel B. Panels A1 and A2 additionally control for donations of money to charity per capita in log, and a dummy variable for the areas where the disaster relief act was applied, respectively. The sample size is 839 except panel A1 (834 observations) due to missing values. 